\title{
Mutations et usage public de l'historiographie polonaise de la seconde moitié du $\mathrm{XX}^{\mathrm{e}}$ siècle $^{1}$
}

\author{
Krysztof Persak
}

Fidèle à l'intitulé même de ce livre, j'évoquerai ici l'impact de l'ouverture des archives en Pologne - l'un des résultats tangibles du changement de régime en 1989 - sur l'écriture de l'histoire la plus récente. Par « histoire la plus récente », j'entends le demi-siècle allant de 1939 à 1989 , période qui correspond à mes propres travaux de recherche et dont je montrerai les principales directions historiographiques prises dans mon pays au cours des vingt dernières années ${ }^{2}$.

\section{LA SITUATION AVANT 1989}

Affirmer qu'avant 1989 ne paraissait aucun livre de valeur sur l'histoire polonaise récente serait sans doute inexact ${ }^{3}$. Si les études historiques sur la Seconde Guerre mondiale étaient importantes, celles portant sur l'après-guerre étaient toutefois soumises à des restrictions

1. Traduit du polonais par Maryla Laurent.

2. La bibliographie de l'histoire polonaise [Bibliografia historii polskiej] publiée chaque année (avec un retard de deux ans) par l'Institut d'histoire de l'Académie des sciences polonaises [Instytut Historii Polskiej Akademii Nauk ou IH PAN] établit la liste exhaustive des travaux historiques parus. Le dernier volume de la BHP est paru en 2007 et il recense les études publiées en 2005. Fin 2008, l'Institut de la mémoire nationale [IPN], en accord avec IH PAN, envisage de mettre en ligne les volumes de la BHP publiés entre 1990 et 2006.

3. S. Ciesielski, W. Wrzesiński, Uwagi o stanie badań nad dziejami powojennej Polski, « Polska 1944-1945-1989. Studia i materiał » [Remarques sur l'état des recherches sur l'histoire de la Pologne d'après-guerre, « La Pologne 1944/1945-1989. Études et documents "), v. 1, Varsovie, 1995. R. Stobiecki, Historiografia PRL. Ani dobra, ani madra, ani piękn.... ale skomplikowana. Studia $i$ szkice [Études historiques de la République populaire de Pologne. Ni bonnes, ni intelligentes, ni belles, mais... compliquées. Études et essais], éd. Trio, Varsovie, 2007. 
politiques majeures. La censure d'État ${ }^{4}$ veillait à maintenir de nombreux tabous. Par ailleurs, des réflexes d'autocensure intervenaient chez les auteurs, de sorte que les historiens évitaient de soulever certaines questions ou de livrer des faits ou des informations dont ils savaient pertinemment que la censure les bloquerait. Dans la pratique, il leur était possible de donner plus de précisions dans les articles spécialisés publiés dans des revues à faible tirage, plutôt que dans les livres destinés au grand public et soumis à un contrôle strict ${ }^{5}$.

Outre les études historiques officielles, et donc surveillées par la censure, de nombreux articles sur l'histoire polonaise récente étaient publiés par les presses parallèles ${ }^{6}$ - le samizdat polonais - à partir de la seconde moitié des années 1970. En 1976, la naissance d'une opposition démocratique structurée puis celle en 1980 du mouvement "Solidarność » éveillèrent dans la société polonaise un véritable intérêt pour l'histoire récente. Retrouver une mémoire historique permettait à celle-ci de reprendre les rênes de son destin par le rappel de ses luttes pour l'indépendance, de ses traditions patriotiques et démocratiques et octroyait, de surcroît, une légitimité nouvelle à l'opposition au régime. A contrario, revenir sur les pages les plus noires de cette histoire récente, sur les exactions et les crimes commis par les communistes, entamait sérieusement la légitimité du pouvoir en place?

Avant 1989, un troisième courant historique existait à l'étranger ${ }^{8}$. En principe, un émigré n'avait aucun accès aux sources archivées en

4. Il n'existe jusqu'à présent aucune étude d'ensemble sur l'activité de la censure durant la deuxième moitié du $\mathrm{xx}^{\mathrm{e}}$ siècle en Pologne. Les publications fragmentaires intéressantes sont : T. Strzyżewski, Czarna księga cenzury PRL [Le livre noir de la censure de la RPP], v. 1-2, Londres, 1977-1978, éd. Aneks. D. Nałęcz, Główny Urzqd Kontroli Prasy 1945-1949 [Bureau principal du contrôle de la presse, 1945-1949], ISP PAN, Varsovie, 1994. A. Pawlicki, Kompletna szarość. Cenzura w latach 1965-1972. Instytucja i ludzie [Totale grisaille. La censure dans les années 1965-1972. L'institution et le personnel], Trio, Varsovie, 2001.

5. Une présentation intéressante des relations entre les historiens polonais et la censure se trouve dans Z. Romek, Cenzura w PRL. Relacje historykówi [La censure en RPP. Récits d'historiens], Neriton, Varsovie, 2000.

6. C. Fedrigo, J. Sygnarski, Papierowa rewolucja [La révolution de papier] : Les éditions clandestines en Pologne communiste, 1976-1990, Fribourg, 1992, Bibliothèque cantonale et universitaire. G. Federowicz, K. Gromadzińska, M. Kaczyńska, Bibliografia podziemnych druków zwartych z lat 1976-1989 [Bibliographie des livres publiés clandestinement, 19761989], Varsovie, 1995, Biblioteka Narodowa. J. M. Preibisz, Jane Leftwich Curry, Polish dissident publications : an annotated bibliography, Praeger, New York, 1982.

7. M. Meller, Rola myślenia o historii w ruchu « Solidarność » w latach 1980-1981 [Rôle de la réflexion sur l'histoire du mouvement « Solidarność » 1980-1981], in M. Kula, Solidarność w ruchu 1980-1981 [Solidarność en mouvement 1980-1981], Varsovie, 2000, éd. NOWA.

8. Z. Jagodziński, Historycy polscy na obczyźnie [Les historiens polonais en exil], "Czasopismo Zakładu Narodowego Imienia Ossolińskich», 1997 [Revue de la 
Pologne. Pourtant dans les années 1980, les historiens vivant en Pologne publiaient de plus en plus souvent en Europe de l'Ouest sous pseudonyme, en particulier dans les Cahiers historiques ${ }^{9}$ [Zeszyty Historyczne] édités par l'Institut littéraire de Jerzy Giedroyć à Maisons-Laffitte. Les presses parallèles rééditaient ensuite clandestinement leurs études en Pologne.

Avant 1989, les archives n'étaient pas totalement fermées en Pologne. Après un délai de communication de trente ans, il était en principe possible d'accéder aux documents de nombreuses institutions d'État (dont certains ministères) quand ceux-ci dépendaient des Archives nationales ${ }^{10}$. En revanche, les dossiers du Parti communiste polonais (POUP) [Parti ouvrier polonais (1942-1948) et Parti ouvrier unifié polonais (1948-1990)] et de multiples autres organisations politiques conservés aux Archives centrales du Comité central du POUP [Centralne Archiwum Komitetu Centralnego PZPR] étaient fermés aux simples chercheurs. Seuls les historiens qui avaient la confiance du pouvoir politique pouvaient les consulter, non sans d'innombrables restrictions arbitraires. Il s'agissait donc en général d'historiens dévoués au système. Les mêmes restrictions s'appliquaient pour les archives particulières comme celles du ministère des Affaires étrangères ou des Archives militaires centrales.

Deux livres thématiquement proches méritent d'être cités comme exemple de ce qu'il était possible de publier dans les années 1980. Vingt ans après leur parution, les connaissances qu'ils apportent restent incontestables. Le premier de ces livres appartient au genre d'historiographie officielle puisqu'il s'agit de la biographie de Władysław Gomułka ${ }^{11}$. L'auteur, Andrzej Werblan, idéologue et membre éminent de l'appareil ${ }^{12}$ (écarté du pouvoir quand il écrit ce livre), a bénéficié

Bibliothèque Ossolineum, 1997, cahier 8]. P. Wandycz, Historycy i historia na emigracji, in Bolesław Orłowski, Nauka polska wobec totalitaryzmów [Les historiens et l'histoire en émigration in La Recherche polonaise face au totalitarisme], Varsovie, 1994. R. Stobiecki, Klio na wygnaniu. Z dziejów polskiej historiografii na uchodźstwie w Wielkiej Brytanii po $1945 r$. [Clio en exil. Histoire des études historiques polonaises en exil en GrandeBretagne après 1945], Poznań, 2005, Wydawnictwo Poznańskie.

9. A. Friszke, Sto osiem tomów jednego pisma, czyli « Zeszyty Historyczne » [Cent huit volumes d'une revue ou les "Cahiers historiques »], Więź, 1994, n 9. J. Krawczyk, J. Szymański, Bibliografia. "Zeszyty Historyczn » 1-110 (1962-1994 [Bibliographie des « Cahiers historiques » 1 à 110, 1962-1994]), Paris, 1996, Instytut Literacki.

10. Les catalogues des archives nationales sont consultables sur Internet: $\mathrm{http}: / /$ baza.archiwa.gov.pl/sezam/index.ph $\mathrm{p}>$.

11. A. Werblan, Wladyslaw Gomulka. Sekretarz generalny PPR [Władysław Gomułka, secrétaire général de la RPP], Varsovie, 1988, Książka i Wiedza.

12. A. Werblan (né en 1924), militant communiste, secrétaire du Comité du POUP de la voïvodie de Kielce (1948-1952), membre du Comité central (CC) du POUP (1956-1981), 
d'un accès privilégié aux Archives centrales du Comité central du POUP. Il est par ailleurs permis de supposer que la censure traita son livre avec bienveillance. Le second ouvrage, La Naissance d'un système de pouvoir. La Pologne de 1943 à 1948, écrit par Krystyna Kersten, est une publication caractéristique d'un(e) historien(e) de l'opposition publiée par les Presses parallèles ${ }^{13}$. L'auteure n'a donc pas eu à s'inquiéter de la censure, mais elle a eu un accès limité aux archives. Elle consulta les documents du gouvernement polonais d'après-guerre ainsi que ceux de plusieurs ministères - dont les publications de sources par l'Institut de l'histoire du Parti du Comité central du POUP dans la série "Archives du mouvement ouvrier » [Zakład Historii Partii KC PZPR, seria « Archiwum Ruchu Robotniczego »]. À ce jour, le livre de Krystyna Kersten reste la meilleure analyse publiée sur la manière dont les communistes se sont emparés du pouvoir en Pologne.

\section{LE NOUVEAU CONTEXTE INSTITUTIONNEL}

La fin de la dictature politique en 1989 modifia fondamentalement les modes d'écriture de l'histoire récente, et ceci principalement pour trois raisons. La première, et la plus importante, tient à la fin des restrictions politiques et de la censure (supprimée officiellement seulement en 1990) et à la liberté de parole, de pensée, de contacts et d'échanges intellectuels avec l'Occident. Le deuxième facteur réside dans le changement psychologique qu'induit cette liberté nouvelle chez les chercheurs et les lecteurs, devenus des hommes libres dans un pays libre. Il n'était ainsi plus nécessaire de légitimer les décisions politiques du pouvoir ou au contraire d'adopter des postures défensives (ou offensives) vis-à-vis de l'histoire officielle, et encore moins d'écrire pour " remonter le moral » de leurs concitoyens. Pour autant, la tendance consistant à « rectifier les mensonges de l'histoire » resta très importante.

directeur du Département de la propagande et de l'agitation (1956-1960) et du Département des sciences et de l'éducation du CC du POUP (1960-1963, 1964-1971), secrétaire du CC du POUP (1974-1980), membre du Bureau politique du CC du POUP (1980), rédacteur en chef du mensuel du POUP Nowe Drogi (1972-1974), directeur de l'Institut des problèmes fondamentaux du marxisme-léninisme auprès du CC du POUP [Instytut Podstawowych Problemów Marksizmu-Leninizmu przy KC PZPR] (1974-1981), vice-président de la Diète de la RPP (1971-1982).

13. K. Kersten, Narodziny systemu władzy. Polska 1943-1948 [La naissance d'un système de pouvoir. La Pologne de 1943 à 1948], Varsovie, 1984, éd. Krąg. K. Kersten, The Establishment of Communist Rule in Poland 1943-1948, University of California Press, Berkeley, 1991. 
La chute du système communiste entraîna la suppression des principales institutions chargées de la création d'une version officielle et apologétique de l'histoire contemporaine. Ce fut le cas de l'École des sciences sociales auprès du Comité central du POUP [Akademia Nauk Społecznych przy Komitecie Centralnym, PZPR] et de l'École des Affaires intérieures [Akademia Spraw Wewnętrznych] qui formaient les officiers de la police politique. La plupart des historiens inféodés au régime communiste qui travaillaient dans ces structures ont trouvé un poste dans des universités de province. Depuis 1989, ils n'ont livré aucun travail de quelque intérêt sur l'histoire récente.

L'ouverture des archives est bien sûr le troisième facteur qui intervint dans les recherches sur l'histoire des cinquante dernières années. Elle s'est déroulée sur deux étapes. Aussitôt après 1989, toutes les archives dites générales et qui relevaient donc de la Direction générale des Archives nationales [Naczelna Dyrekcja Archiwów Państwowych], mais aussi dans une large mesure les archives particulières comme celles du ministère des Affaires étrangères [MSZ] et les archives militaires, ont été accessibles aux chercheurs sans entraves. En 1990, après la dissolution du Parti communiste, la transmission de ses dossiers aux Archives des documents nouveaux [Archiwum Akt Nowych ou AAN] fut un événement majeur. Les AAN ont également pris en charge l'ensemble des Archives centrales du Comité central du POUP où se trouvent les papiers d'innombrables organisations politiques ${ }^{14}$. Tous les chercheurs peuvent accéder aux documents réservés par le passé à ceux qui étaient « bien en cour », qu'il s'agisse des documents de certains services du Comité central du POUP ou de la documentation interdite comme les archives du Bureau politique, du Secrétariat du Comité central du POUP, ou de celles des chancelleries des Premiers secrétaires du Comité central.

Le délai de communication de trente ans des archives n'est pas rigoureusement respecté au point que le projet d'une nouvelle réglementation visant à supprimer ce délai est actuellement en cours d'élaboration par la Direction générale des Archives nationales [Naczelna Dyrekcja Archiwów Państwowych]. Il est donc relativement facile d'obtenir le droit de lever le délai de communication. Seuls les services du ministère des Affaires étrangères et ceux des archives militaires restent encore pointilleux sur les délais. Et depuis l'année 2000, par décision du ministre de la Culture et du Patrimoine national, les dossiers des partis et organisations politiques (donc principalement ceux du POUP) ne sont plus soumis au délai de communication.

$14 \mathrm{Un}$ annuaire des documents qui se trouvent aux AAN se trouve sur :

$<$ http://www.archiwa.gov.pl/repository///books/AAN_Informator_o_zasobie_archiwa lnym.pd $\mathrm{f}>$. 
Après 1989, les archives du ministère de l'Intérieur et du Bureau de la défense de l'État qui renfermaient les dossiers de la police politique sont restées fermées à l'exception de quelques passe-droits. Il était impossible de consulter les inventaires des archives ou les dossiers qui évoquaient des opérations de surveillance ou d'intervention. Seule la documentation administrative (comptes rendus et rapports de réunions), ou celle des interrogatoires, étaient accessibles.

La deuxième étape de l'ouverture des archives est liée à la création de l'AAN en 2000. Les archives de la police communiste et des autres services secrets y ont été transférées pour être accessibles aux personnes ayant fait l'objet d'une surveillance politique policière ainsi qu'aux chercheurs et journalistes. D'un point de vue réglementaire, tous ces documents sont libres d'accès (ceux sur les opérations menées, sur les personnes concernées et sur les agents) et ne sont pas astreints au délai de communication de trente ans. Dans la pratique, leur consultation reste difficile tant par manque d'instruments de recherche que du fait de la lenteur avec laquelle ils sont délivrés à ceux qui souhaitent les consulter.

\section{RÉPRESSIONS ET RÉSISTANCES}

Comment ces changements sont-ils intervenus sur les études historiques polonaises? Immédiatement après 1989, il fut beaucoup question de « rectifier les mensonges de l'histoire » et de combler ses " pages blanches », et donc de décrire et explorer les événements auparavant frappés d'interdit. Les chercheurs, manifestement fascinés par la récente ouverture des archives, étaient le plus souvent en quête évidente de sensationnel. À peine découvrait-on un document surprenant qu'on le publiait aussitôt dans la presse assorti d'un commentaire minimal. Par exemple, le dossier du projet de constitution de la République populaire de Pologne de 1952 sur lequel figuraient les corrections manuscrites de Staline. Ce document fut découvert dans les coffres du Comité central du POUP et remis à la presse par Andrzej Garlicki ${ }^{15}$. Pareilles parutions dans les quotidiens et les hebdomadaires de

15 J. Zakrzewska, A. Garlicki, Zatwierdzanie Konstytucji PRL, « Polityk » 1990, n 28 [Ratification de la Constitution de la RPP, Polityka, 1990, $\mathrm{n}^{\circ} 28$ ]. Staline a inscrit personnellement plus de cinquante corrections sur les feuillets du projet de la Constitution. L'édition critique du document a été publiée par : K. Persak, « Troskliwy opiekun i światly doradca Polski Ludowe » - poprawki Józefa Stalina do Konstytucji PRL z 22 lipca 1952 roku [Joseph Staline, protecteur soucieux et conseiller éclairé de la Pologne populaire : ses corrections à la Constitution de la PRL du 22 juillet 1952], in D. Stola, M. Zaremba, PRL. Trwanie i zmiana [Durer et changer], éd. WSPiZ, Varsovie, 2003. 
documents normalement destinés à des publications spécialisées, indiquent combien la société polonaise dans son ensemble était intéressée par son histoire récente. Cet intérêt n'a pas décru depuis. La presse polonaise rapporte de façon quasi quotidienne des faits historiques du dernier demi-siècle.

L'une des caractéristiques des récentes études historiques consiste à publier de nombreux documents-sources. Après 1989, plusieurs collections spécialisées dans la publication des textes sources ${ }^{16}$ ont été créées. Rendre des documents nouveaux accessibles au monde scientifique est évidemment utile, surtout quand ceux-ci révèlent des choses absolument surprenantes. J'en veux pour exemple la découverte par Andrzej Paczkowski des résultats réels du référendum de 1946, falsifiés par les communistes (jusque-là, selon les données officielles, le POUP aurait bénéficié d'un soutien de $68 \%$; les documents découverts montrent qu'en réalité, le résultat était inverse : $73 \%$ des Polonais avaient voté contre le « Bloc démocratique » et donc contre le POUP et ses alliés) ${ }^{17}$. L'importante fréquence de la publication des documents authentiques n'est pas uniquement due à la fascination pour les découvertes. Elle découle aussi du besoin de prouver les résultats des nouvelles recherches, proposant ainsi au lecteur de nouvelles thèses avec la documentation qui les justifie. Les collections publiant les documents originaux avec un commentaire plus ou moins développé permettent ensuite la parution de monographies.

Immédiatement après 1989 se dessine une forte tendance à faire toute la lumière sur le passé récent. Les nouvelles études historiques demandent des comptes à la dictature communiste, un nombre important de publications concernant la répression communiste et ses

16. Les plus importantes sont la collection « Dokumenty do dziejów PR » [Les documents sur l'histoire de la RPP] publiée par l'Institut des études politiques de l'Académie des sciences [Instytut Studiów Politycznych PAN] (18 volumes); la collection « Tajne dokumenty Biura Polityczneg " [documents secrets du Bureau politique] publiée par les éditions polonaises Aneks à Londres (6 volumes; la collection « Archiwum Sejmu PR » [archives de la Diète de la RPP] publiée par les éditions de la Diète [Wydawnictwo Sejmowe] (6 volumes; la collection " Dokument » [Documents] publiée par l'IPN (24 volumes ; la collection "Archiwum Kultury» [Les archives de "Kultur »] publiée par les éditions Czytelnik ( 9 volumes) ; la collection " Polska mniej znana 1944-1989 » [Une Pologne moins connue, 1944-1989] publiée par les AAN (4 volumes); la collection «Polskie dokumenty dyplomatyczn » [Les documents diplomatiques polonais] publiée par l'Institut polonais des Affaires internationales [Polski Instytut Spraw Międzynarodowych] (7 volumes) ; la collection "Archiwum Emigrac » [Archives de l'émigration] publiée par l'université Nicolas Copernic de Toruń ( 27 volumes). Un nombre conséquent de documents-sources (parfois en plusieurs volumes, a également été publié hors collection.

17. A. Paczkowski, Referendum z 30 czerwca $1946 \mathrm{r}$. Przebieg $i$ wyniki [Le référendum du 30 juin 1946. Déroulement et résultats], Varsovie; 1994, (« Dokumenty do dziejów PR », [Les documents sur l'histoire de la RPP], v. 4), éd. ISP PAN. 
victimes. Ainsi peut-on lire dans la presse les noms des personnes condamnées à mort pendant la période stalinienne ${ }^{18}$. De nombreux articles sont consacrés aux tribunaux des années 1944-1956, aux procès politiques et au régime des prisons et des camps de travail.

Un autre courant historique s'intéresse au fonctionnement de la résistance armée clandestine qui s'opposa à l'instauration du communisme dans l'immédiate après-guerre, mais aussi à la résistance polonaise en lutte contre l'occupation soviétique des confins orientaux de l'ancienne Pologne dans les années 1939-1941. En l'occurrence, il s'agissait là de véritables «pages blanches» de l'histoire, les recherches partant pratiquement de zéro. Certains historiens abandonnèrent même leurs études sur la résistance polonaise contre l'occupation allemande au point que les structures et les activités de la résistance anticommuniste sont aujourd'hui mieux connues que celles de la résistance antinazie. Toutefois, malgré l'abondance de monographies très précises sur les formes de résistance contre le régime communiste, il n'existe pas encore d'ouvrage de synthèse susceptible de donner une vue d'ensemble sur la question. Peut-être l'atlas monumental publié par l'IPN comble-t-il dans une certaine mesure ce manque $^{19}$. La création de cet institut et l'ouverture des dossiers de la police politique permit d'ailleurs un nouvel essor aux recherches aux recherches sur l'activité de la résistance armée clandestine et la répression qu'elle suscita.

L'activité de l'IPN permit aussi un développement rapide des recherches sur l'appareil de la Sûreté communiste. Une vingtaine d'ouvrages sur le sujet sont parus depuis l'an 2000. Ce sont surtout des études de cas (cases studies) et des recueils reproduisant des documents originaux ayant généralement pour titre " La Sûreté nationale et... ", suivi du milieu politique ou professionnel concerné ${ }^{20}$. Les critiques

18. S. Pająk, Lista straconych $w$ więzieniach PRL $w$ latach 1944-1956 [Liste des personnes exécutées dans les prisons de la RPP, 1944-1956], Wokanda, 1991, n 1, 3-7, 10-20, 23, 25-26 ; Straceni w polskich więzieniach 1944-1956 [Exécutés dans les prisons polonaises, 1944-156], éd. Retro, Lublin, 1994.

19. R. Wnuk, Atlas polskiego podziemia niepodleglościowego 1944-1956 [Atlas de la résistance polonaise contre le communisme, 1944-1956], Varsovie-Lublin, 2007, éd. IPN. L'Atlas comporte une bibliographie. La première monographie sur la résistance polonaise armée contre les Soviétiques dans les années 1939-1941 a été récemment publiée par Rafał Wnuk, "Za pierwszego Sowiet». Polska konspiracja na Kresach Wschodnich II Rzeczypospolitej (wrzesien 1939-czerwiec 1941) [Première occupation soviétique. La résistance polonaise dans les Confins orientaux de la Deuxième République (septembre 1939-juin 1941], éd. IPN, Varsovie, 2007.

20. J. Wołoszyn, Chronić $i$ kontrolować. UB wobec środowisk $i$ organizacji konspiracyjnych młodzieży na Lubelszczyźnie [Protéger et contrôler. La Sûreté face aux cercles et organisations de jeunesse dans la région de Lublin] (1944-1956), Varsovie, 2007; 
reprochent à la plupart de ces travaux, souvent à juste titre, d'exploiter les dossiers des archives de la Sûreté sans les avoir suffisamment confrontés à d'autres sources (mais dans les documents du Parti communiste, il est rarement question de la police politique). Aucune synthèse satisfaisante n'a été rédigée à ce jour sur l'appareil de sécurité communiste. Il n'existe pas non plus de monographies sur l'activité de ses composantes de base (espionnage, contre-espionnage, lutte contre l'opposition politique, etc.) mais des travaux sont en cours sur ces questions. De nombreuses controverses portent sur la nécessité ou non de révéler l'identité des collaborateurs secrets de la police politique. Elles ne sont pas séparables d'un autre problème de la vie politique polonaise, à savoir la lustration ou procédure qui consiste à examiner le passé des personnes occupant des postes publics de responsabilité sous l'angle de leur collaboration avec les services de la sécurité communiste ou de leur appartenance à ceux-ci ${ }^{21}$.

Les historiens s'intéressèrent aussi beaucoup à l'émigration politique de l'après-guerre et à l'Église catholique sous le régime communiste. Ce sont là, semble-t-il, des sujets à la mode. Il y a eu beaucoup de travaux sur le mensuel Kultura ${ }^{22}$ paraissant en France et sur la vie politique des Polonais émigrés à Londres après la Seconde Guerre mondiale ${ }^{23}$. Les publications concernant l'Église s'intéressent

R. Terlecki, Aparat bezpieczeństwa wobec emigracji politycznej i Polonii [La Sûreté dans son approche de l'émigration politique polonaise et des Polonais à l'étranger], Varsovie, 2005; Ł. Kamiński, G. Waligóra, Kryptonim «Pega». Stużba Bezpieczeństwa wobec Towarzystwa Kursów Naukowych 1978-1980 [Cryptonyme « Pégas ». La Sûreté dans son approche de l'Association des formations scientifiques 1978- 1980], Varsovie, 2008; Ł. Kamiński, G. Waligóra, Kryptonim "Wasal ». Stużba Bezpieczeństwa wobec Studenckich Komitetów Solidarności 1977-1980 [Cryptonyme "Vassaux ». La Sûreté dans son approche des Comités estudiantin de Solidarność, 1977-1980], Varsovie, 2007; A. Dziurok, Metody pracy operacyjnej aparatu bezpieczeństwa wobec kościolów $i$ zwiazków wyznaniowych 1945-1989 [Les méthodes de travail de la Sûreté dans leur approche des églises et des cercles confessionnels, 1945-1989], Varsovie, 2004.

21. P. Grzelak, Wojna o lustrację [La guerre de la lustration], Trio, Varsovie, 2005; B. Wildstein, Dhugi cień PRL-u, czyli dekomunizacja, której nie bylo [L'ombre très longue de la RPP, ou la dé-communisation qui n'a pas eu lieu], Arcana, Cracovie, 2005 ; J. Woleński, Lustracja jako zwierciadlo [Le miroir de la lustration], Universitas, Cracovie, 2007; A. Romanowski, Rozkosze lustracji [Les délices de la lustration], Universitas, Cracovie, 2007.

22. Giedroyc i Kultur », Wrocław, 1999. J. Korek, Paradoksy paryskiej « Kultur ». Styl i tradycje myślenia politycznego [Les paradoxes de Kultura. Le style et les traditions de la pensée politique du cercle polonais de Maisons-Laffitte], UMCS, Lublin, 2000. R.Habielski, Dokąd nam iść wypada? Jerzy Giedroyc od "Buntu Mtodyc » do "Kultur " [Où convient-il d'aller? Jerzy Giedroyć de la Révolte des jeunes à Kultura], Więź, Varsovie, 2006 ; I. Hoffman, "Kultur " paryska. Twórcy, dzieto, recepcja [Kultura de Paris. Les hommes, l'œuvre, les lecteurs], UMCS, Lublin, 2007.

23. R. Habielski, Polski Londyn [Le Londres polonais], Wyd. Dolnośląskie, Wrocław, 2000 ; A. Friszke, R. Habielski, P. Machcewicz, Druga wielka emigracja 1945-1990 [La 
surtout aux rapports qu'elle entretint avec l'État et sur les répressions subies par les catholiques ${ }^{24}$. Le regard porté sur l'Église est donc avant tout extérieur à celle-ci puisqu'il passe par les documents de l'État (ceux du bureau des Affaires religieuses), du Parti communiste et de l'appareil de sécurité. Car les archives de l'Église, paradoxalement, restent difficilement accessibles (de fait aussi fermées que celles du parti communiste par le passé...) ; elle n'en autorise l'accès qu'à ses propres historiens, en qui elle a toute confiance.

Les études historiques sur la République populaire de Pologne sont avant tout d'ordre politique. Jusqu'à présent, la période stalinienne est la plus étudiée parce que les archives sont accessibles (le délai de communication de trente ans étant passé) et aussi parce qu'elle est la plus intéressante par son caractère particulièrement répressif. Les chercheurs s'intéressent également beaucoup à l'opposition démocratique des années 1970, au mouvement « Solidarność », à l'état de guerre et à la chute du système communiste. Finalement, l'époque la moins étudiée couvre les vingt années entre 1956 et 1976 à l'exception des crises politiques et sociales $(1956,1968,1970,1976)$ qui ont donné lieu à une littérature importante (l'année 1956 en particulier).

Le fait que la plupart des chercheurs se soient concentrés sur les manifestations sociales massives, les protestations, les grèves, mais aussi la résistance armée ou politique contre le pouvoir communiste ou encore sur les diverses formes de répression, a favorisé la mise en place d'un paradigme dominant dans l'historiographie polonaise actuelle. Selon ce schéma, l'histoire polonaise après la Seconde Guerre mondiale n'aurait été qu'une suite de conflits entre un pouvoir oppressif et étranger au peuple et une nation s'opposant (toujours) à ce pouvoir et se révoltant (de façon cyclique). Ce qui manque à un tel tableau, ce sont les études sur le degré de soutien dont bénéficiait le régime communiste dans la société, sur la manière dont il était accepté au sein de la population, sur l'opportunisme et sur la manière dont les

deuxième grande émigration], v. 1-3, Więź, Varsovie, 1999 ; A. Friszke, Warszawa nad Tamiza. Z dziejów polskiej emigracji politycznej po drugiej wojnie światowej [Varsovie sur Tamise. L'histoire de l'émigration politique après la Seconde Guerre mondiale], ISP PAN, Varsovie, 1994 ; T. Radzik, Z dziejów spoleczności polskiej w Wielkiej Brytanii po drugiej wojnie światowej (1945-1990) [L'histoire des Polonais en Grande-Bretagne après la Seconde Guerre mondiale, 1945-1990], UMCS, Lublin, 1991.

24. A. Dudek, R. Gryz, Komuniści i Kościól w Polsce (1945-1989) [Les communistes et l'Église en Pologne], Znak, Cracovie, 2003 ; J. Żaryn, Dzieje kościola katolickiego w Polsce (1944-1989) [L'histoire de l'Église catholique en Pologne, 1944-1989], Neriton, Varsovie, 2003 ; Z. Zieliński, Kościól w Polsce 1944-2002 [L'Église catholique en Pologne, 1944-2002], Polskie Wydawictwo Encyklopedyczne, Radom, 2003. 
gens s'adaptaient au système ${ }^{25}$ en place. Alors même que le Parti communiste fut l'acteur dominant de la scène politique, une trop faible attention est aujourd'hui portée à son fonctionnement comme institution et "machine du pouvoir " ou comme expression de l'idéologie communiste. Aucun ouvrage sur ce sujet n'a été publié après 1989 et ceux qui sont antérieurs à cette date sont partiaux et hagiographiques.

Les recherches portant sur l'histoire sociale restent à la traîne de l'histoire politique, du moins quant à leur nombre. Il est clair qu'après 1989, les faits majeurs devaient être établis en priorité, le temps d'une réflexion poussée devant venir ensuite. Un certain nombre de volumes importants ont été publiés ces dernières années sur divers aspects sociaux de la République populaire. Il faut citer ici les travaux très novateurs de Dariusz Jarosz qui, depuis plusieurs années, étudie les relations entre le pouvoir et divers groupes sociaux qui se situent aux échelons inférieurs de l'échelle sociale. Le professeur Jarosz s'intéresse à des sources souvent laissées de côté par les autres historiens pour montrer comment le projet communiste se trouva confronté à une réalité qui lui résistait ${ }^{26}$. Plusieurs jeunes chercheurs travaillent également sur l'histoire sociale. À titre d'exemple, citons les trois livres publiés ces dernières années par Krzysztof Kosiński sur la vie et les attitudes de la jeunesse en Pologne communiste ${ }^{27}$.

Une tension perceptible est apparue dernièrement entre les chercheurs spécialisés en histoire politique et ceux en histoire sociale, particulièrement sur l'usage et l'interprétation des dossiers de la police politique. Paweł Machcewicz apporte pourtant la preuve qu'il est possible de trouver un moyen terme. Son livre, L'Année 1956 en

25. B. Brzostek, M. Zaremba, Polska 1956-1976 : w poszukiwaniu paradygmatu [Pologne 1956-1976: la recherche d'un paradigme], Pamięć $i$ Sprawiedliwość, 2006, nº 2.

26. D. Jarosz, Polityka władz komunistycznych w Polsce w latach 1948-1956 a chtopi [La politique du pouvoir communiste en Pologne et les paysans, 1948-1956], Varsovie, 1998, DiG. Idem, Polacy a stalinizm 1948-1956 [Les Polonais et le stalinisme], Wyd. Instytut Historii PAN, Varsovie, 2000 ; idem, " Masy pracujqce przede wszystki ". Organizacja wypoczynku w Polsce 1945-1956 [Les masses laborieuses avant tout. L'organisation du repos en Pologne, 1945-1956], Wyd. Instytut Historii PAN, Varsovie, 2003. D. Jarosz, M. Pasztor, Afera mięsna. Fakty $i$ konteksty [L'affaire de la viande. Faits et contextes], Wyd. Centrum Edukacji Europejskiej, Torun, 2004.

27. K. Kosiński, O nową mentalność. Życie codzienne w szkolach 1945-1956 [Pour une nouvelle mentalité. La vie quotidienne dans les écoles, 1945-1956], Trio, Varsovie, 2000 ; idem, Nastolatk '81. Świadomość młodzieży w epoce Solidarnośc » [Les teenagers 1981. La conscience de la jeunesse à l'époque de Solidarność], Trio, Varsovie, 2002 ; idem, Oficjalne i prywatne życie mlodzieży w czasach PRL [La vie officielle et la vie privée de la jeunesse à l'époque de RPP], Rosner \& Wspólnicy, Varsovie, 2006. 
Pologne ${ }^{28}$, analyse la pensée banale et quotidienne des Polonais et leur mobilisation en cette année cruciale pour leur pays. Machcewicz se sert des rapports de la police politique comme d'une source sur l'opinion de la population et élabore, à partir de là, une sorte de baromètre qui évalue les attitudes de la société polonaise en 1956. Son travail associe de façon harmonieuse les démarches propres aux chercheurs en histoire politique à celles des chercheurs en histoire sociale.

\section{LA POLOGNE, L'URSS ET LES MINORITÉS NATIONALES}

Avant 1989, les relations entre la Pologne et l'Union soviétique formaient un sujet particulièrement tabou. Bien plus que l'ouverture des archives en Pologne, celle (partielle) des archives postsoviétiques autorisée en 1991 par Boris Eltsine fut d'une importance décisive pour la recherche. Un travail considérable de collecte d'informations fut accompli par la Commission militaire des archives qui, dans la première moitié des années 1990, entreprit de photocopier plus d'un demi million de pages de ces archives russes ${ }^{29}$. Il devint ainsi possible de travailler sur l'occupation soviétique du territoire polonais dans les années 1939-1941 (en 1939, Hitler occupa $48 \%$ du territoire polonais et Staline $52 \%$ ) à partir des documents sources, sujet qui n'avait pratiquement pas été traité jusque-là. La question des répressions, élément essentiel de la politique soviétique à l'égard des Polonais, fut largement représentée parmi ces travaux, de même qu'un certain nombre d'études sur les transformations sociales, économiques et culturelles pendant l'occupation soviétique. L'accès aux archives postsoviétiques permit aussi de vérifier les estimations antérieures des études réalisées par les historiens polonais vivant à l'étranger, notamment sur les chiffres des déportations en Sibérie. On estimait le nombre de Polonais déportés entre 1,2 et 1,5 million $^{30}$. Les sources soviétiques indiquent qu'au cours des quatre vagues de déportation entre 1940 et 1941, environ 320000 personnes furent déportées tandis que 100000 autres furent persécutées

28. P. Machcewicz, Polski rok 1956 [L'année 1956 en Pologne], Oficyna Wydawnicza Mówią Wiek, Varsovie, 1993.

29. Informacja o wynikach pracy Wojskowej Komisji Archiwalnej $w$ archiwach Federacji Rosyjskiej w okresie wrzesien 1992-czerwiec 1993 [Information sur les résultats du travail de la Commission militaire des archives dans les archives de la Fédération de Russie. Septembre 1992-juin 1993], Biuletyn Wojskowej Stużby Archiwalnej, n 16, 1993.

30. W. Wielhorski, Deported Poles in Soviet Captivity (1939-1956), Eastern Polish Council and Polish Association of Former Soviet Political Prisoners, Londres, 1956; J. Siedlecki, Losy Polaków w ZSRR w latach 1939-1986 [Le sort des Polonais en URSS, 1939-1956], éd. Stowarzyszenie Polskich Kombatantów, Londres, 1987, p. 44-46. 
par d'autres moyens ${ }^{31}$. De nombreux travaux publiés concernent les répressions soviétiques à l'égard des Polonais après 1944 (arrestations et déportation des membres de la résistance polonaise, des politiciens et militants anticommunistes, des mineurs de Silésie ${ }^{32}$ transformés en véritables esclaves, etc.). Les listes des personnes persécutées peuvent être établies après examen des archives soviétiques. Vingt-quatre volumes de l'Index des personnes persécutées [Indeks represjonowanych] publiés par les soins de la Fondation du Centre la "Charte » [Fundację Ośrodek « Karta »], et en collaboration avec « Memorial », l'association russe pour la mémoire des victimes des répressions politiques, sont parus ${ }^{33}$.

Le crime de Katyń - où 22000 prisonniers de guerre et prisonniers politique polonais ont été passés par les armes au printemps 1940, sur ordre du Bureau politique du PCUS - est un symbole de l'occupation soviétique et de tous les malheurs infligés aux Polonais par l'URSS au $\mathrm{XX}^{\mathrm{e}}$ siècle. L'accès aux archives russes, avec le geste politique fort du président Eltsine livrant aux Polonais le document de la décision du Politburo du 5 mars 1940, ainsi que les travaux archéologiques et les exhumations sur le lieu des charniers, permirent de faire toute la lumière sur cette tragédie. La bibliographie sur Katyń est considérable, je retiens ici l'édition en quatre volumes des sources soviétiques majeures $^{34}$.

Après 1945, le rapport de dépendance absolue de la Pologne vis-àvis du Kremlin était un élément politique majeur. Pourtant, à l'exception de plusieurs livres sérieux et quelques publications de sources, les études sur les relations entre la Pologne et l'URSS restent très lacunaires. Même chose pour la soviétologie. Les raisons de cette absence historiographique résident avant tout dans les nouvelles difficultés d'accès aux archives russes, et notamment aux documents postérieurs à 1953 .

31. S. Ciesielski, W. Materski, A. Paczkowski, Represje sowieckie wobec Polaków i obywateli polskich [Les répressions soviétiques des Polonais et citoyens polonais], Fundacja Ośrodka Kart, Varsovie, 2002.

32. Z. Woźniczka, Z Górnego Śląska do sowieckich lagrów [De Haute Silésie aux camps de travail soviétiques], Śląsk, Katowice, 1996.

33. La base de données de ce projet de documentation éditoriale ( 843 mille entrées) se trouve sur : http://indeks.karta.org.pl/.

34. W. Materski, Katyń. Dokumenty zbrodni [Katyń. Documents d'un crime] ; Jeńcy niewypowiedzianej wojny: sierpień 1939-marzec 1940 [Les prisonniers d'une guerre non déclarée : août 1939-mars 1940], v. ; Zaglad a: marzec-czerwiec 1940 [L'extermination : mars à juin 1940], v. ; Losy ocalatych: lipiec 1940-marzec 1943 [Les destins des survivants juillet 1940-mars 1943], v. ; Echa Katyni a: kwiecień 1943-marzec 2005 [L'écho de katyn : avril 1943-mars 2005], Varsovie, 1995-2006, wyd. Naczelna Dyrekcja Archiwów Państwowych. 
La question des minorités nationales était l'une de celles qui, avant 1989, subissaient un contrôle particulièrement rigoureux de la censure. La République populaire de Pologne se targuait en effet d'être un État homogène du point de vue ethnique. Dès lors, le pouvoir voyait d'un mauvais œil tout rappel à l'encontre de ce discours officiel. Une fois la censure abolie, les pages blanches sur le sujet furent vite comblées. Un grand nombre d'études furent consacrées à la politique communiste en matière de minorités nationales ${ }^{35}$. Elles concernèrent notamment les groupes les plus importants numériquement : allemand $^{36}$, ukrainien ${ }^{37}$, biélorusse $^{38}$ et juif ${ }^{39}$. Des livres consacrés aux minorités lituanienne ${ }^{40}$, slovaque $^{41}$, tatare ${ }^{42}$ ou grecque ${ }^{43}$ furent également.

La problématique des minorités ethniques devint un nouveau sujet de recherche à la mode. La fascination pour les différences ethniques et culturelles appartient à un phénomène social plus vaste, qui se manifesta, entre autre, par un intérêt passionné vis-à-vis des terres occidentales de la Pologne d'après-guerre qui avaient été allemandes avant 1939. Le besoin de connaître le passé allemand de ces territoires apparut en histoire, mais aussi en littérature et en photographie (expositions de photographies anciennes, éditions de beaux livres, etc.).

Un climat favorable permit également d'aborder les pages sombres des relations entre les citoyens polonais et les non-polonais de la RPP. Outre le terme mis à la censure et l'ouverture des archives, le

35. E. Mironowicz, Polityka narodowościowa PRL [La politique de la RPP à l'égard des minorités nationales], Białoruskie Towarzystwo Historyczne, Białystok, 2000; L. Olejnik, Polityka narodowościowa Polski $w$ latach 1944-1960 [La politique polonaise à l'égard des minorités nationales, 1944-1960], Łódź, 2003, Uniwersytet Łódzki.

36. P. Madajczyk, Niemcy polscy 1944-1989 [Les Allemands polonais, 1944-1960], Oficyna Naukowa, Varsovie, 2001.

37. R. Drozd, Polityka władz wobec mniejszości ukraińskiej w Polsce w latach 19441989 [La politique officielle à l'égard de la minorité ukrainienne en Pologne, 1944-1989], Tyrs, Varsovie, 2001.

38. E. Mironowicz, Białorusini w Polsce 1944-1949 [Les biélorusses en Pologne, 1944-1949], PWN, Varsovie, 1993.

39. J. Tomaszewski, Najnowsze dzieje Żydów w Polsce [L'histoire la plus récente des Juifs en Pologne], PWN, Varsovie, 1993.

40. K. Tarka, Litwini w Polsce 1944-1997 [Les Lituaniens en Pologne, 1944-1997], Opole, 1998, Uniwersytet Opolski.

41. J. Kwiek, Z dziejów mniejszości slowackiej na Spiszu i Orawie w latach 1945 1957 [Histoire de la minorité slovaque de Spisz et Orawa, 1945-1957], Cracovie, 2002, éd. Towarzystwo Słowaków w Polsce.

42. A. Miśkiewicz, Tatarska legenda. Tatarzy polscy 1945-1989 [La légende tatare. Les Tatares polonais, 1945-1989], Białystok, 2003, Krajowa Agencja Wydawnicza.

43. M. Wojecki, Uchodźcy polityczni z Grecji w Polsce 1948-1975 [Les exilés politiques grecs en Pologne, 1948-1975], Jelenia Góra, 1989, Karkonoskie Towarzystwo Naukowe. 
recouvrement par la Pologne de sa souveraineté nationale fut un facteur psychologique non négligeable de ce nouveau climat. Pour dire les choses simplement, se sentir en sécurité dans un pays libre, démocratique et stable permit de traiter plus sereinement des événements où les Polonais avaient mal agi vis-à-vis de ses concitoyens.

Les études concernant les ressortissants allemands, soutenues par les institutions et les fondations scientifiques allemandes, furent les plus poussées. Parmi le grand nombre de travaux sur la situation de la population allemande en Pologne après 1945 (dont l'édition de quatre volumes de documents ${ }^{44}$ ), les historiens ne font pas l'impasse sur les diverses manifestations de vengeance qui se sont déroulées juste après la guerre (camps de rétention des Allemands, répressions individuelles ou collectives ${ }^{45}$ ). La question de l'expulsion des Allemands de Pologne (conformément à la décision de la conférence de Postdam en 1945) ainsi que celle de l'émigration volontaire des Allemands par la suite, figurent également en bonne place ${ }^{46}$. (Il existe aussi une monographie sur les prisonniers allemands en $\mathrm{RPP}^{47}$ ).

De nombreux travaux s'intéressèrent au tragique conflit entre les Polonais et les Ukrainiens entre 1939 et $1947^{48}$. Les victimes polonaises furent de loin les plus nombreuses, mais les études nouvelles ne négligent pas les souffrances que connurent les Ukrainiens, comme par exemple l'opération militaire « Vistule » (1947) au cours de laquelle les Lemkoviens (assimilés aux Ukrainiens) furent expulsés de leurs terres (Beskides) pour être dispersés à l'ouest et au nord de la RPP ${ }^{49}$. Un cycle

44. W. Borodziej, H. Lemberg, Niemcy w Polsce 1945-1950. Wybór dokumentów [Les Allemands en Pologne, 1945-1950. Choix de documents], v. 1-4, Neriton, Varsovie, 2000-2001.

45. W. Stankowski, Obozy i inne miejsca odosobnienia dla niemieckiej ludności cywil$n e j w$ Polsce $w$ latach 1945-1950 [Camps et autres lieux d'isolement de la population civile allemande, 1945-1950], Bydgoszcz, 2002, éd. Akademia Bydgoska.

46. B. Nitschke, Wysiedlenie czy wypędzenie? Ludność niemiecka w Polsce w latach 1945-1949 [Expulsés ou chassé? La population allemande en Pologne, 1945-1949], Toruń, 2004, éd. Adam Marszałek. W. Borodziej, A. Hajnicz, Kompleks wypędzenia [Le complexe de l'expulsion], Znak, Cracovie, 1998. S. Jankowiak, Wysiedlenie i emigracja ludności niemieckiej $w$ polityce wladz polskich $w$ latach 1945-1970 [L'expulsion de la population allemande et la politique officielle polonaise, 1945-1970], Varsovie, 2005, IPN.

47. J. Kochanowski, W polskiej niewoli. Jeńcy niemieccy w Polsce 1945-1950 [Les prisonniers allemands en Pologne, une détention polonaise, 1945-1950], Varsovie, 2001, Neriton.

48. A. L. Sowa, Stosunki polsko-ukraińskie 1939-1947 [Les relations polono-ukrainiennes, 1939-1947], Cracovie, 1998, éd. Towarzystwo Sympatyków Historii. G. Motyka, Tak byto w Bieszczadach. Walki polsko-ukrainskie 1943-1948 [Cela se passa ainsi dans les Bieszczady. Les luttes entre Polonais et Ukrainiens, 1943-1948], Volumen, Varsovie, 1999.

49. R. Drozd, Droga na zachód. Osadnictwo ludności ukraińskiej na ziemiach zachodnich i pólnocnych Polski $w$ ramach akcji Wist [La route de l'Ouest. Installation forcée des populations ukrainiennes à l'ouest et au nord de la Pologne, action militaire «Vistule »], Varsovie, 1997, Tyrs. 
de conférences eut lieu entre 1997 et 2005 sous le haut patronage de l'association mondiale des résistants polonais pendant la Seconde Guerre mondiale (AK) et de l'association des Ukrainiens de Pologne ${ }^{50}$. Ce fut une initiative importante pour permettre, de part et d'autre, de surmonter les malentendus et les préjugés nationaux.

De nouvelles études prêtèrent aussi une grande attention à l'histoire des Juifs de Pologne et aux relations polono-juives (du reste pas seulement à l'époque contemporaine ; nombreux sont les travaux qui explorent le Moyen Âge et les siècles suivants). Certaines monographies sont consacrées aux communautés juives dans différentes régions de Pologne, mais aussi aux organisations sociales et politiques juives. Il n'existe pas encore de synthèse sur l'histoire des Juifs en Pologne après la Seconde Guerre mondiale ${ }^{51}$. Les pogromes de Kielce ${ }^{52}$ et de Cracovie $^{53}$ ainsi que la campagne antisémite ${ }^{54}$ menée en 1968 par le pouvoir polonais, ont fait l'objet de plusieurs publications.

Les études sur 1'Holocauste ${ }^{55}$ se développent également. Après 1989, l'Institut historique juif [Żydowski Instytut Historyczny], la Commission principale chargée de l'étude des crimes nazis [Główna Komisja Badania Zbrodni Hitlerowskich], les groupes d'études auprès des musées sur les sites des camps d'extermination (Oświęcim,

50. R. Niedzielko, Polska-Ukraina. Trudne pytania [Pologne-Ukraine. Des questions difficiles], v. 1-10, Varsovie, 1998-2006.

51. B. Szaynok, Ludność żydowska na Dolnym Ślasku 1945-1950 [La population polonaise en Basse-Silésie, 1945-1950], Wrocław, 2000, Uniwersytet Wrocławski. G. Berendt, Żydzi na gdańskim rozdrożu (1945-1950) [Les Juifs à la croisée des chemins à Gdańsk, 1945-1950], Gdańsk, 2000, Uniwersytet Gdański. G. Berendt, Życie żydowskie w Polsce w latach 1950-1956. Z dziejów Towarzystwa Spoleczno-Kulturalnego Żydów w Polsce [La vie juive en Pologne, 1950-1956. Histoire de la société socioculturelle des Juifs en Pologne], Gdańsk, 2006, Uniwersytet Gdański. A. Grabski, Żydowski ruch kombatancki w Polsce w latach 1944-1949 [Le mouvement des combattants juifs en Pologne, 1944-1949], Varsovie, 2002, Trio. A. Grabski, Działalność komunistów wśród Żydów w Polsce (1944-1949) [Activité des communistes dans les milieux juifs en Pologne, 19441949], Varsovie, 2004, Trio. N. Aleksiun, Dokad dalej ? Ruch syjonistyczny w Polsce 1944-1950 [Plus loin pour où? Le mouvement sioniste en Pologne, 1944-1950], Varsovie, 2002, Trio.

52. B. Szaynok, Pogrom Żydów $w$ Kielcach 4 lipca 1946 [Le pogrome du 4 juillet 1946 à Kielce], Bellona, Varsovie, 1992. Ł. Kamiński, J. Żaryn, Wokót pogromu kieleckiego [Autour du pogrome de Kielce], Varsovie, 2006, IPN.

53. A. Cichopek, Pogrom Żydów w Krakowie 11 sierpnia 1945 [Le pogrome du 11 août 1945 à Cracovie], Varsovie, 2000, Żydowski Instytut Historyczny.

54. D. Stola, Kampania antysyjonistyczna w Polsce 1967-1968 [La campagne antisioniste de 1967-1968 en Pologne], Varsovie, 2000, ISP PAN. J. Eisler, Polski rok 1968 [L'année 1968 en Pologne], Varsovie, 2006, IPN.

55. N. Aleksiun, Historiografia na temat Zaglady $i$ stosunków polsko-żydowskich $w$ okresie drugiej wojny światowej [Les études historiques sur la Shoah et les relations polono-juives au cours de la Seconde Guerre mondiale], Zaglada Żydów. Studia $i$ Materialy, $\mathrm{n}^{\circ} 1,2005$. 
Majdanek) ne sont plus seuls à traiter la question. Dans les recherches, le problème de l'attitude des Polonais face à la Shoah et ses victimes ${ }^{56}$ est de plus en plus souvent abordé. L'activité du Centre de recherches sur l'Holocauste [Centrum Badań nad Holocaustem - Polish Centre for Holocaust Research], créé en 2003, mérite une attention particulière. Dans ses publications, il soulève notamment la question des dénonciations et des chantages perpétrés par les Polonais à l'égard des Juifs, voire même la participation directe de Polonais à des crimes contre les Juifs ${ }^{57}$. Avant 1989, ces questions étaient totalement occultées à cause de la censure. Le débat national qui eut lieu en 2001-2002 à propos du crime de Jedwabne ${ }^{58}$ et l'édition du Livre blanc en deux volumes par l'IPN eurent un impact majeur sur le développement de ce courant de recherches.

Dix-huit ans après la chute du communisme, l'état des connaissances sur l'histoire polonaise après la Seconde Guerre mondiale s'est considérablement accru. L'histoire récente est indubitablement le domaine d'études historiques qui se développe le plus vite. L'intérêt de toute la société polonaise pour cette histoire est considérable, bien que les recherches restent hélas très dispersées. Il est assez paradoxal qu'à la différence d'autres pays postcommunistes, aucune institution d'importance n'ait été créée en Pologne après 1989 pour s'occuper exclusivement de l'histoire contemporaine. Tel est le cas de l'Institut de l'histoire récente de l'Académie des sciences tchèque ou le Centre d'études sur l'histoire récente à Postdam [Zentrum für Zeithistorische Forschung Potsdam] ou l'Institut de l'histoire récente de Ljubljana [Inštitut za novejšo zgodovino]. Après 2000, l'Institut de la mémoire nationale s'est vu confier la coordination des recherches sur l'histoire contemporaine, mais il reste par principe chargé d'étudier la répression, l'activité de l'appareil de la Sûreté ainsi que les crimes communistes et nazis (même si des efforts ont été faits dès l'origine pour dépasser ce cadre). Par ailleurs, les controverses suscitées par les documents de la police politique font qu'une partie des chercheurs souhaitent se distancier de l'IPN.

56. A. Żbikowski, Polacy $i$ Żydzi pod okupacja niemieckq 1939-1945. Studia i materiaty [Les Polonais et les juifs sous l'occupation allemande, 1939-1945. Etudes et documents], Varsovie, 2006, IPN.

57. J. Grabowski, « Ja tego Żyda znam ». Szantażowanie Żydów w Warszawie 19391943 [Ce Juif-là, je le connais ! Le chantage fait aux Juifs à Varsovie entre 1939 et 1943], Varsovie, 2004, IFiS PAN. Barbara Engelking, "Szanowny panie gistap ». Donosy do wladz niemieckich $w$ Warszawie i okolicach $w$ latach 1940-1941 [Monsieur Guestipo. Les délations adressées aux autorités allemandes à Varsovie et dans ses environs, 1940-1941], Varsovie, 2003, IFiS PAN.

58. Paweł Machcewicz, Krzysztof Persak, Wokót Jedwabnego [Autour de Jedwabne], v. : Studia [Etudes ; v. : Dokumenty [Documents], Varsovie, 2002, IPN. 